\title{
Theoretical and experiment studies on the adsorption of formate species on the surface of catalyst
}

\author{
Hongwei Gao ${ }^{\mathrm{a}, *}$, Hong $\mathrm{He}^{\mathrm{b}}$, Changbin Zhang ${ }^{\mathrm{b}}$, Tingxia Yan ${ }^{\mathrm{c}}$ \\ a Institute of Watershed Science and Environmental Ecology, Wenzhou Medical College, Zhejiang 325035, China \\ ${ }^{\mathrm{b}}$ Research Center for Eco-Environmental Sciences, Chinese Academy of Sciences, Beijing, 100085, China \\ ${ }^{\mathrm{c}}$ State property administration department, Wenzhou Medical College, Zhejiang, 325035, China
}

\section{A R T I C L E I N F O}

\section{Article history:}

Received 4 March 2008

Received in revised form 21 March 2008

Accepted 21 March 2008

Available online 4 April 2008

\section{Keywords:}

DFT

In situ DRIFTS

Simulated spectra

Formate

$\mathrm{Cu}-\mathrm{Al}_{2} \mathrm{O}_{3}$ catalyst

\begin{abstract}
A B S T R A C T
Density functional theory (DFT) calculations and in situ diffuse reflectance infrared Fourier transform spectroscopy (DRIFTS) were performed to study the formation and adsorption of formate species over the $\mathrm{Cu}-\mathrm{Al}_{2} \mathrm{O}_{3}$ catalyst. The geometrical structures and vibration spectra of calculated models were obtained at the PBE1PBE level of DFT and compared with the corresponding experimental values. Theoretical calculations show that the calculated IR spectra are in good agreement with the experimental spectroscopic results. The mechanism of the catalyst deactivation and regeneration was also discussed during the process of the removal of $\mathrm{HCHO}$ on the $\mathrm{Cu}-\mathrm{Al}_{2} \mathrm{O}_{3}$ catalyst at the room temperature.
\end{abstract}

(c) 2008 Elsevier B.V. All rights reserved.

\section{Introduction}

Formaldehyde ( $\mathrm{HCHO}$ ) is the dominating volatile organic compound (VOC) in the indoor environment [1]. Moreover, HCHO is very bad for health. It can cause the nasal tumors, respiratory tract, eye membranes irritation and skin irritation [2].

Catalytic oxidation is an effective method for removing VOC because VOC can be oxidized into CO over catalyst at much lower temperature than those of thermal oxidation [3-5]. However, catalytic oxidation is still very difficult to eliminate $\mathrm{HCHO}$ at the room temperature.

Using adsorbents can effectively remove the $\mathrm{HCHO}$ at the room temperature. This method has been studied by many researchers [6-8]. Eriksson et al. [6] have reported the study about the removal of gaseous $\mathrm{HCHO}$ using potassium permanganate, activated carbon and aluminum oxide and so on. Arthur [7] found that HCHO concentration was dropped from $1.3-1.8$ to $0.2-0.3 \mathrm{ppm}$ within a few hours but returned to its initial level after 1-5 days through filter beds of potassium permanganate in a mobile house with active airflow. Sekine and Nishimura [8] have reported that copper oxides could react with $\mathrm{HCHO}$ with the high reactivity at the room temperature. Recently, Sekine and Nishimura [8] have found that activated carbon particles and manganese oxides not only reduced indoor $\mathrm{HCHO}$ concentration from 0.21 to $0.04 \mathrm{ppm}$ for more than

\footnotetext{
* Corresponding author. Tel./fax: +86 57786699570 .

E-mail address: gaohongw369@hotmail.com (H. Gao).
}

7 months, but also enhanced the loss of $\mathrm{HCHO}$ gas from building material in apartments.

Although using adsorbents is effective method to remove $\mathrm{HCHO}$ at the room temperature, there is still a limited understanding on the formation and configuration of intermediate involved in the reaction. The mechanism of catalyst deactivation and regeneration is also still not clear.

In this paper, we reported on studies of the formation and adsorption of formate species over the $\mathrm{Cu}-\mathrm{Al}_{2} \mathrm{O}_{3}$ catalyst using experimental and theoretical methods. The study aims to utilize in situ DRIFTS and stimulant spectrum toward the understanding of the mechanism of the catalyst deactivation and regeneration during the process of the removal of $\mathrm{HCHO}$ on the $\mathrm{Cu}-\mathrm{Al}_{2} \mathrm{O}_{3}$ catalyst at the room temperature.

\section{Experimental}

\subsection{Catalyst preparation}

Utilized $\mathrm{Al}_{2} \mathrm{O}_{3}$ (gamma type) has a total BET surface area of $250 \mathrm{~m}^{2} / \mathrm{g}$ as supporter of $\mathrm{Cu}-\mathrm{Al}_{2} \mathrm{O}_{3}$ (Cu metal loading: $10 \mathrm{wt} . \%$ ) catalyst, which was prepared by an impregnation method with an aqueous solution of copper nitrate, followed by evaporation to dryness in a rotary evaporator under a reduced pressure at $333 \mathrm{~K}$. The wet sample obtained was dried at $393 \mathrm{~K}$ for $12 \mathrm{~h}$, and then calcined in air at $873 \mathrm{~K}$ for $3 \mathrm{~h}$. Before the catalytic tests, the catalysts were sieved into 40-60 meshes. 


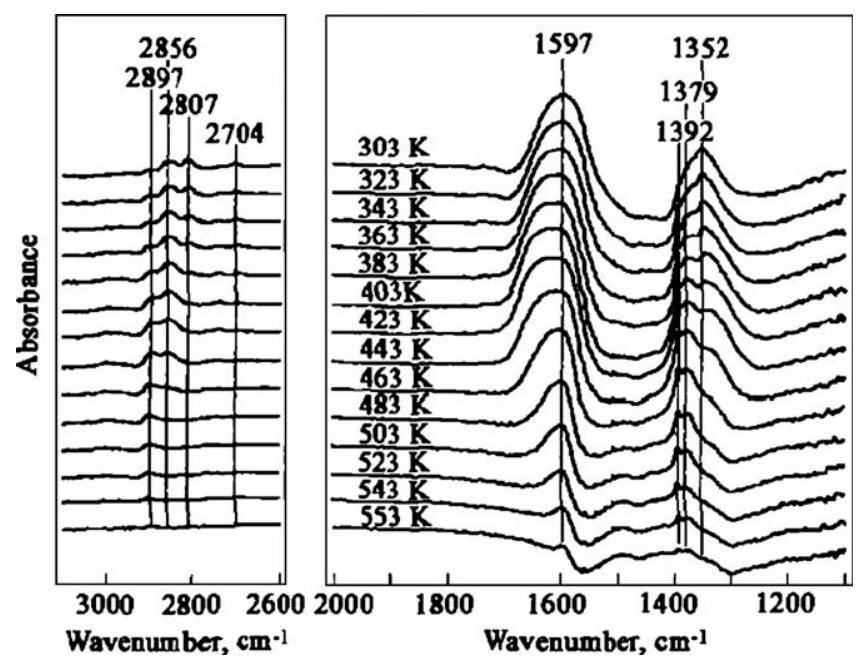

Fig. 1. In situ DRIFT spectra of $\mathrm{Cu}-\mathrm{Al}_{2} \mathrm{O}_{3}$ catalyst in a flow of $\mathrm{N}_{2}$ mixture at various temperatures (303-553 $\mathrm{K}$ ) after $\mathrm{HCHO}+\mathrm{O}_{2}$ adsorption for $600 \mathrm{~min}$ on the $\mathrm{Cu}-\mathrm{Al}_{2} \mathrm{O}_{3}$ catalyst.

\subsection{DRIFTS}

DRIFT and in situ DRIFT spectra were recorded in a NEXUS 670FTIR equipped with a smart collector and a liquid $\mathrm{N}_{2}$ cooled MCT

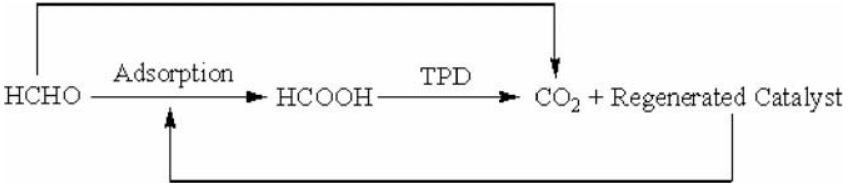

Scheme 1. The process of the $\mathrm{HCHO}$ elimination over $\mathrm{Cu}-\mathrm{A1}_{2} \mathrm{O}_{3}$.

detector. The sample (about $30 \mathrm{mg}$ ) for study was finely grounded and placed in a ceramic crucible. A now of feed gas mixture was controlled by mass now meters. All spectra were measured with a resolution of $4 \mathrm{~cm}^{-1}$ and accumulating 100 scans. A background spectrum was subtracted from each spectrum, respectively.

\subsection{Theoretical section}

All calculations were performed using the Gaussian98 program [9]. The properties of the calculated models were determined through the application of density functional theory (DFT) using the PBE1PBE [10] function and LANL2DZ [11] basis set. PBE1PBE is the generalized-gradient-approximation exchange-correlation functional of Perdew, Burke, and Ernzerhof. The LANL2DZ effective core potential basis set was used for all of the calculations. The LANL2DZ basis replaces the $1 \mathrm{~s}$ through $2 \mathrm{p}$ electrons of the heavy atoms with a potential field for a considerable computational savings. A double- $\zeta$ quality dunning basis was used for the light atoms

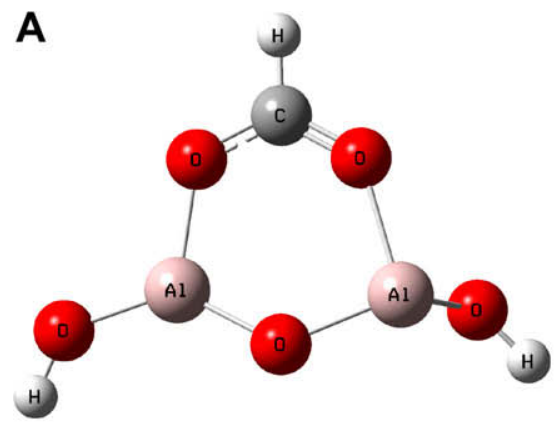

B

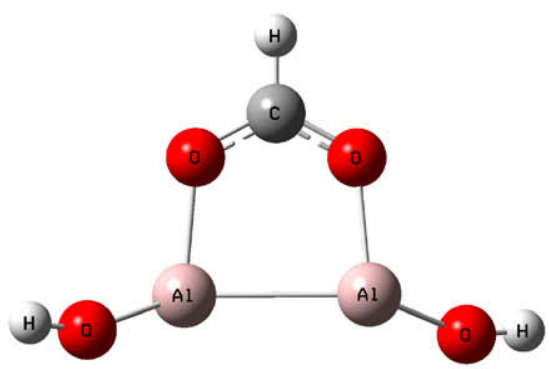

C

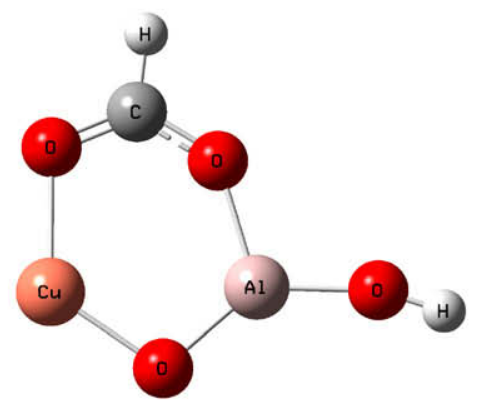

E

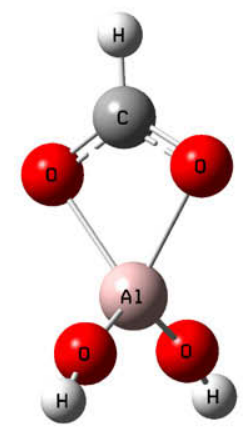

D

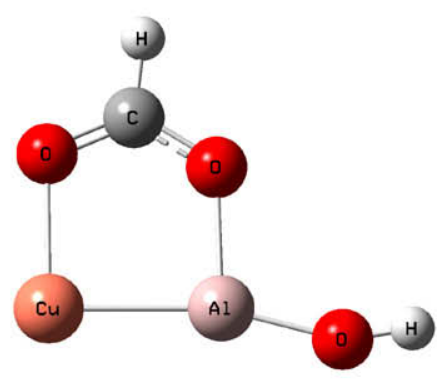

$\mathbf{F}$

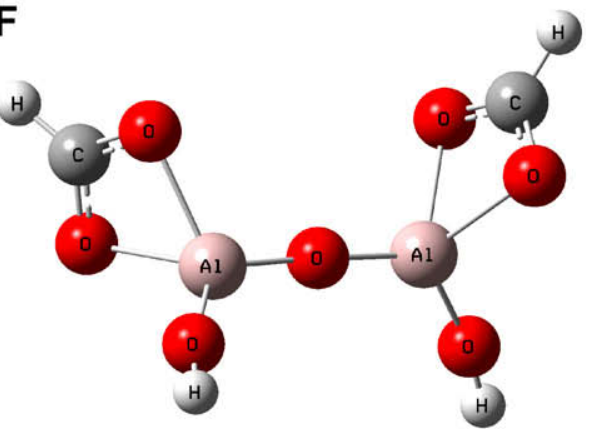

Fig. 2. Optimized configuration of calculation models for formate species adsorption on the $\mathrm{Cu}-\mathrm{Al}_{2} \mathrm{O}_{3}$ catalyst 
and the remaining heavy atom electrons. Stability calculations confirmed the ground-state configuration of all the wave functions.

\section{Results and discussion}

\subsection{Experimental spectra}

Fig. 1 shows the in situ DRIFT spectra of the $\mathrm{Cu}-\mathrm{Al}_{2} \mathrm{O}_{3}$ catalyst in a flow of $\mathrm{N}_{2}$ at various temperatures (303-553 K) after $\mathrm{HCHO}+\mathrm{O}_{2}$ adsorption for $600 \mathrm{~min}$ on the $\mathrm{Cu}-\mathrm{Al}_{2} \mathrm{O}_{3}$. Exposure of this catalyst to the fed gas resulted in the appearance of eight peaks (2897, 2856, 2807, 2704, 1597, 1392, 1379 and $1352 \mathrm{~cm}^{-1}$ ). According to previous studies, two strong bands at 1597 and $1352 \mathrm{~cm}^{-1}$ were ascribed to $v_{\text {as }}(\mathrm{COO})$ and $v_{\mathrm{s}}(\mathrm{COO})$ [12-15], the small and shoulder bands at 2897, 2856, 2807 and $2704 \mathrm{~cm}^{-1}$ were assigned to $v(\mathrm{C}-\mathrm{H})$ [13-15], and the peaks at 1392 and $1379 \mathrm{~cm}$ were assigned to $\delta(\mathrm{C}-\mathrm{H})[13-15]$. No peak of the adsorbed HCHO could be observed, even at room temperature. The findings showed that a large amount of $\mathrm{HCOOH}$ was formed over the $\mathrm{Cu} / \mathrm{Al}_{2} \mathrm{O}_{3}$ surface.

3.2. Mechanism for the formation of absorbed formate species over $\mathrm{Cu}-\mathrm{Al}_{2} \mathrm{O}_{3}$ catalyst

On the basis of our previous results, we propose Scheme 1 for the process of the $\mathrm{HCHO}$ elimination over $\mathrm{Cu}-\mathrm{A}_{2}{ }_{2} \mathrm{O}_{3}$.
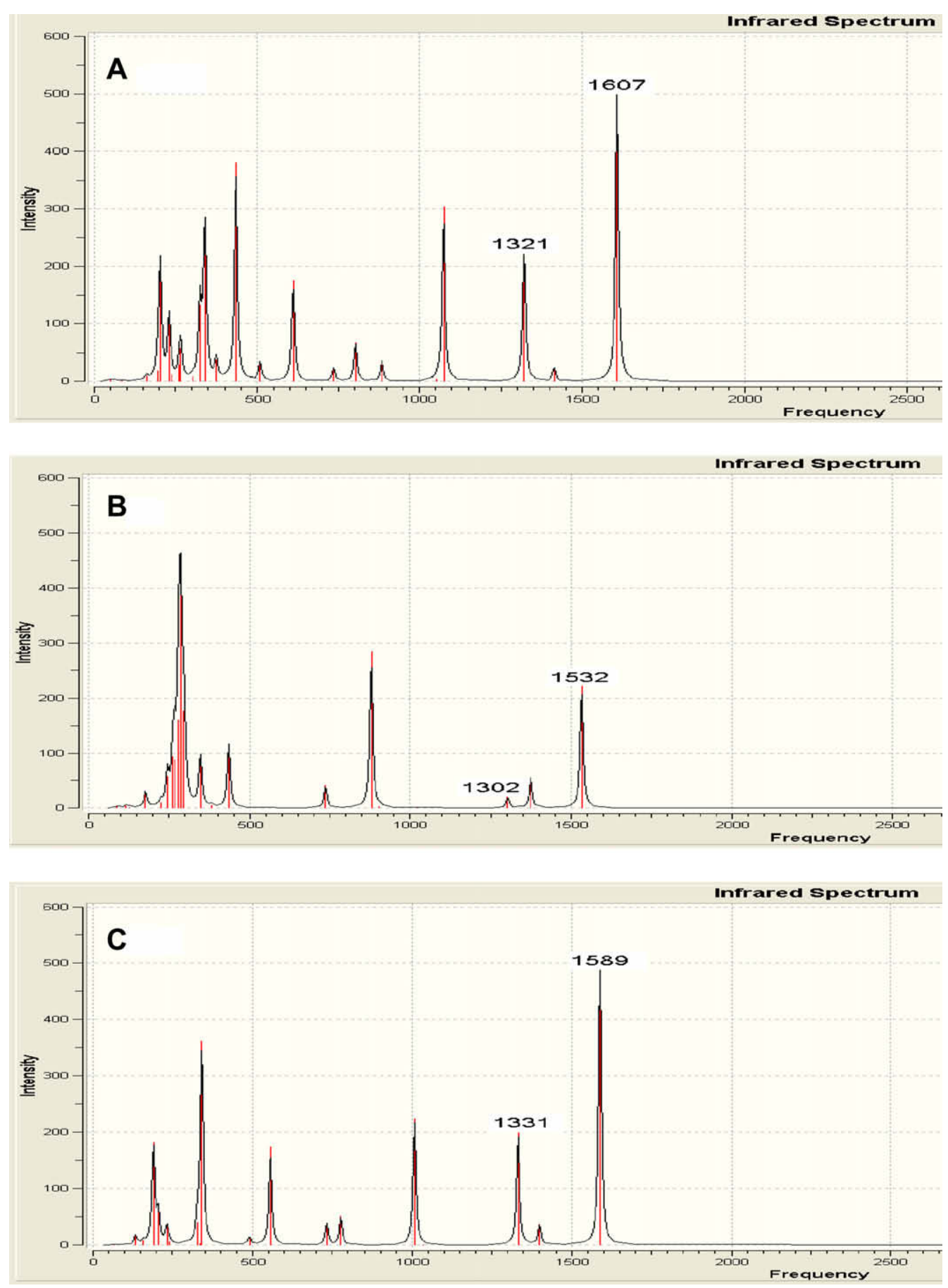

Fig. 3. Calculated vibration IR spectra for the models (A-C) at DFT-PBE1PBE/LANL2DZ level. 
When the catalyst was exposed to $\mathrm{HCHO}+\mathrm{O}_{2}$ mixture for $600 \mathrm{~min}$, the deactivated $\mathrm{Cu}-\mathrm{A}_{1}{ }_{2} \mathrm{O}_{3}$ catalyst was heated to $773 \mathrm{~K}$ in a flow of $40 \mathrm{~cm}^{3} / \mathrm{min}$ helium. HCHO firstly adsorbed on the $\mathrm{Cu}-\mathrm{A}_{2}{ }_{2} \mathrm{O}_{3}$ catalyst surface, and then was oxidized into $\mathrm{HCOOH}$ at the room temperature. The results of the in situ DRIFTS, Density functional theory calculations and temperature programmed desorption (TPD) showed that HCHO was completely oxidized into $\mathrm{HCOOH}$ over $\mathrm{Cu}-\mathrm{Al}_{2} \mathrm{O}_{3}$ at the room temperature. With increasing the temperature in a flow of helium, $\mathrm{HCOOH}$ was completely decomposed into $\mathrm{CO}_{2}$ over the catalyst surface, and the deactivated $\mathrm{Cu}-\mathrm{Al}_{2} \mathrm{O}_{3}$ is regenerated at the same time. In addition, although $\mathrm{Cu}$ had no obvious influence on the adsorption of $\mathrm{HCHO}$ on $\mathrm{Al}_{2} \mathrm{O}_{3}, \mathrm{Cu}$ dramatically lowered the decomposition temperature of $\mathrm{HCOOH}$ into $\mathrm{CO}_{2}$. It was shown that the $\mathrm{Cu}-\mathrm{Al}_{2} \mathrm{O}_{3}$ catalyst had a good ability for the removal of $\mathrm{HCHO}$, and appeared to be promising for its application in destroying $\mathrm{HCHO}$ at the room temperature.

\subsection{Optimized structure}

In order to investigate the structure of the adsorption of formate species on the $\mathrm{Cu}-\mathrm{Al}_{2} \mathrm{O}_{3}$ catalyst, we designed six calculated models (A-F). The optimized structures of these calculation models are
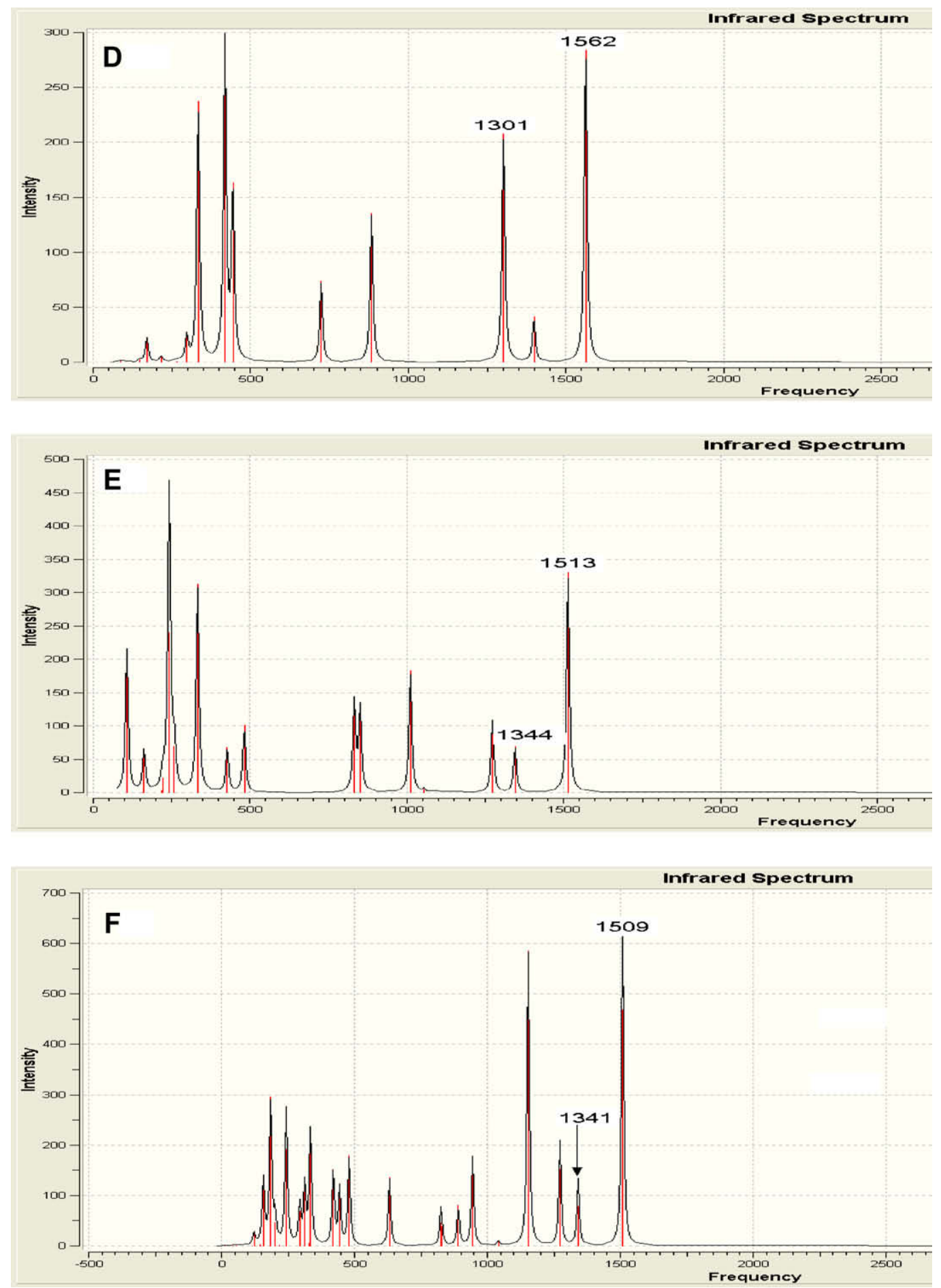

Fig. 4. Calculated vibration IR spectra for the models (D-F) at DFT-PBE1PBE/LANL2DZ level. 
Table 1

Calculated vibration frequencies (in $\mathrm{cm}^{-1}$ ) and IR intensity (in $\mathrm{km} / \mathrm{mol}$ ) for the calculated model at PBE1PBE/LANL2DZ level, and corresponding frequencies in the experimental gas-phase spectra

\begin{tabular}{llll}
\hline Model & Frequency $\left(\mathrm{cm}^{-1}\right)$ & Intensity $(\mathrm{km} / \mathrm{mol})$ & Vibration mode \\
\hline A & 1607 & 510 & $v_{\text {as }}(\mathrm{COO})$ \\
& 1321 & 237 & $v_{\mathrm{s}}(\mathrm{COO})$ \\
$\mathrm{B}$ & 1532 & 226 & $v_{\text {as }}(\mathrm{COO})$ \\
& 1302 & 55 & $v_{\mathrm{s}}(\mathrm{COO})$ \\
$\mathrm{C}$ & 1589 & 515 & $v_{\text {as }}(\mathrm{COO})$ \\
& 1331 & 203 & $v_{\mathrm{s}}(\mathrm{COO})$ \\
$\mathrm{D}$ & 1562 & 290 & $v_{\text {as }}(\mathrm{COO})$ \\
& 1301 & 208 & $v_{\mathrm{s}}(\mathrm{COO})$ \\
$\mathrm{E}$ & 1513 & 332 & $v_{\mathrm{as}}(\mathrm{COO})$ \\
& 1344 & 69 & $v_{\mathrm{s}}(\mathrm{COO})$ \\
$\mathrm{F}$ & 1509 & 468 & $v_{\mathrm{as}}(\mathrm{COO})$ \\
& 1341 & 79 & $v_{\mathrm{s}}(\mathrm{COO})$ \\
Experiment $\left(\mathrm{cm}^{-1}\right)$ & 1597 & & $v_{\text {as }}(\mathrm{COO})$ \\
& 1352 & & $v_{\mathrm{s}}(\mathrm{COO})$ \\
\hline
\end{tabular}

plotted in Fig. 2. The optimized $\mathrm{C}=\mathrm{O}$ bond length in formate species for the models (A-F) is about 1.23-1.24 $\AA$, which is within $2 \%$ error of the experimental value of $1.22 \AA$. The $\mathrm{C}-\mathrm{H}$ bond length in formate species for the models (A-F) is about $1.09 \AA$, which is in good agreement with experimental value of $1.09 \AA$.

\subsection{Comparison of simulated and experimental spectra}

The optimized geometries were taken as the basis for the calculation of IR frequencies by a normal coordinate analysis. Simulation spectra of $\mathrm{Cu}-\mathrm{Al}_{2} \mathrm{O}_{3}$ are depicted in Figs. 3 and 4. Calculated vibration frequencies (in $\mathrm{cm}^{-1}$ ) and IR intensity (in $\mathrm{km} / \mathrm{mol}$ ) and corresponding frequencies in the experimental gas-phase spectra are listed in Table 1.

The calculated antisymmetric stretching vibration modes of the adsorbed formate species for the models (A-F) are 1607, 1532, 1589, 1562, 1513 and $1509 \mathrm{~cm}^{-1}$, respectively (Figs. 3 and 4). In comparison with the same experimental frequency of $1597 \mathrm{~cm}^{-1}$, the error is on average about $10 \mathrm{~cm}^{-1}$ for model (A), $-65 \mathrm{~cm}^{-1}$ for model (B), $-8 \mathrm{~cm}^{-1}$ for model (C), $-35 \mathrm{~cm}^{-1}$ for model (D), $-84 \mathrm{~cm}^{-1}$ for model (E) and $-88 \mathrm{~cm}^{-1}$ for model $(\mathrm{F})$. For the same experimental frequency of $1597 \mathrm{~cm}^{-1}$, overestimation of experimental frequency values is about $0.62 \%$ for model $(A)$; underestimation of experimental frequency values is about $4.07 \%$ for model (B), $0.50 \%$ for model (C), $2.19 \%$ for model (D), $5.25 \%$ for model (E) and 5.51\% for model (F). The calculated frequencies of model (A) at $1607 \mathrm{~cm}^{-1}$ with $510 \mathrm{~km} / \mathrm{mol}$ intensity is relatively good matches of the most intense bands at $1597 \mathrm{~cm}^{-1}$ in the experimental spectrum (Fig. 1). The calculated frequencies of model (C) at $1589 \mathrm{~cm}^{-1}$ with $515 \mathrm{~km} / \mathrm{mol}$ intensity is also in good agreement with the experimental value of $1597 \mathrm{~cm}^{-1}$ (Fig. 1).

The calculated symmetric stretching vibration modes of the adsorbed formate species for the models (A-F) are 1341, 1302, 1331, 1301, 1344 and $1321 \mathrm{~cm}^{-1}$, respectively (Fig. 3 and Fig. 4). In comparison with the same experimental frequency of $1352 \mathrm{~cm}^{-1}$, the error is on average about $-31 \mathrm{~cm}^{-1}$ for model (A), $-50 \mathrm{~cm}^{-1}$ for model (B), $-21 \mathrm{~cm}^{-1}$ for model (C), $-51 \mathrm{~cm}^{-1}$ for model (D), $-8 \mathrm{~cm}^{-1}$ for model (E) and $-11 \mathrm{~cm}^{-1}$ for model (F). For the same experimental frequency of $1352 \mathrm{~cm}^{-1}$, underestimation of experimental frequency values is about $2.29 \%$ for model (A), $3.69 \%$ for model (B), $1.55 \%$ for model (C), 3.77\% for model (D), $0.59 \%$ for model (E) and $0.81 \%$ for model (F). The calculated frequency of model (E) at $1344 \mathrm{~cm}^{-1}$ with $69 \mathrm{~km} / \mathrm{mol}$ intensity is relatively good matches of the peak at $1352 \mathrm{~cm}^{-1}$ in the experimental spectrum (Fig. 1).

Although the calculated symmetric stretching vibration mode of the adsorbed formate species of model (E) is better than that of model $\mathrm{A}$, there is big error between the calculated and experimental antisymmetric stretching vibration modes of the adsorbed formate species for model (E). Therefore, the spectra of model (A) simulated by DFT-PBE1PBE evidently best match the experimental counterparts for overwhelming majority of the calculated models (A-F) considered in the present study.

\section{Conclusion}

The calculated IR spectrum for the model $(A)$ is of reasonable similarity to the corresponding experimental spectrum. Furthermore, calculated antisymmetric and symmetric stretching vibration modes of the adsorbed acetate species for the model (A) are in good agreement with experimental data. The calculations show clearly that simulating infrared spectra with density functional theory (DFT) quantum mechanical method can be considered as the advantageous auxiliary tool for analyzing the mechanism of the formate species adsorption over the $\mathrm{Cu}-\mathrm{Al}_{2} \mathrm{O}_{3}$ catalyst.

\section{Acknowledgement}

This work was financially supported by the College Science Fund for Start-up Program of Wenzhou Medical College.

\section{References}

[1] C. Yu, D. Crump, J. Build. Environ. 33 (1998) 357

[2] J.J. Collins, R. Ness, R.W. Tvl, J. Toxicol. Pharmacol. 34 (2001) 17.

[3] J.J. Spivey, J. Ind. Eng. Chem. Res. 26 (1987) 2165.

[4] S. Stiré, S. Minicò, C. Crisafulli, Appl. Catal. B 40 (2003) 43.

[5] S. Stiré, S. Minicò, C. Crisafulli, J. Catal. Commun. 2 (2001) 229.

[6] B. Eriksson, L. Johnanssin, I. Svedung, in: The nordest symposium on air pollution abatement by filtration and respiratory protection. Filtration of form aldehyde contaminated indoor air. Copenhagen, 1980.

[7] D. Arthur, A report to the HCHO Institute by Arthur D. Little lnc., Cambridge, MA, 1981.

[8] Y. Sekine, A. Nishimura, Atmos. Environ. 35 (2001) 2001.

[9] M.J. Frisch, G.W. Trucks, H.B. Schlegel, G.E. Scuseria, M.A. Robb, J.R. Cheeseman, V.G. Zakrzewski, J.A. Montgomery, R.E. Stratmann, J.C. Burant, S. Dapprich, J.M. Millam, A.D. Daniels, K.N. Kudin, M.C. Strain, O. Frakas, J. Tomasi, V. Barone, M. Cossi, R. Cammi, B. Mennucci, C. Pomelli, C. Adamo, S.Clifford, J. Ochterski, G.A. Petersson, P.Y. Ayala, Q. Cui, K. Morokuma, D.K. Malick, A.D. Rabuck, K. Raghavachari, J.B. Foresman, J. Cioslowski, J.V.Ortiz, A.G. Baboul, B.B. Stefanov, G. Liu, A. Liashenko, P. Piskorz, I. Komaromi, R. Gomperts, R.L. Martin, D.T. Fox, T. Keith, M.A. AI-Laham, C.Y. Peng, A Nanayakkara, C. Gonzalez, M. Challacombe, P.M.W. Gill, B.G.Johnso, W. Chen, W. Wong, J.L. Andress, M. Head-Gordon, E.S. Replogle and J.A. Pople, Gaussian, Inc., Pittsburgh, PA, 1998.

[10] J.P. Perdew, K. Burke, M. Ernzerhof, Phys. Rev. Lett. 77 (1996) 3865

[11] P.J. Hay, W.R. Wadt, J. Chem. Phys. 82 (1985) 299.

[12] F. Boccuzzi, A. Chiorino, M. Manzoli, J. Power Sources 118 (2003) 304.

[13] G.J. Millar, C.H. Rochester, K.C. Waugh, J. Catal. 155 (1995) 52

[14] F.Z. Liu, M.M. Yang, W. Zhou, J. Electro. Chem. Comm. 5 (2003) 276.

[15] G.A. Popova, Y.A. Chesalov, T.V. Andrushkevich, J. Mol. Catal. 158 (2000) 345 